\title{
EDUCAÇÃO A DISTÂNCIA: CENÁRIO ATUAL E PERSPECTIVAS
}

Jeong Cir Deborah Zaduski, Adriano Rodrigues Ruiz

Universidade do Oeste Paulista - Unoeste, Mestrado em Educação, Presidente Prudente, SP. E-mail: deborah zaduski@hotmail.com

\section{RESUMO}

O presente artigo traz uma análise do contexto corrente de cursos e práticas exercidos na modalidade a distância, apresentando alternativas viáveis na busca de propostas metodológicas que valorizem o aluno, o diálogo crítico reflexivo e a busca pela formação de indivíduos autônomos, protagonistas em seu processo de ensino/aprendizagem. A metodologia adotada é a pesquisa crítica-reflexiva dos conteúdos bibliográficos sobre o tema que apontaram como conclusão a existência de alternativas viáveis para a promoção de um ensino a distância mais contextualizado e significativo que contemple as diferentes capacidades e competências dos alunos.

Palavras-chave: Educomunicação. Metodologias Ativas. Educação a distância.

\section{DISTANCE EDUCATION: CURRENT SCENARIO AND PROSPECTS}

\begin{abstract}
This paper presents an analysis of the current context of courses and practices exercised in the distance environment, presenting viable alternatives in the search for methodological proposals that value the student, the critical and reflective dialogue and the search for the formation of autonomous individuals, protagonists in the process of teaching / learning. The methodology adopted is the critical-reflexive research of bibliographic contents about this subject that showed as conclusion that there are viable alternatives for the promotion of a more contextualized and significant model of distance learning, that contemplates the different skills and competences of students.
\end{abstract}

Keywords: Educommunication. Active methodologies. Distance education. 


\section{INTRODUÇÃO}

Estamos na era da educação digital. O cenário otimista nasce da projeção dos dados pesquisados pelo Censo EAD 2013/2014 ${ }^{1}$ realizado pela Associação Brasileira de Educação a Distância (ABED) os quais estimam o crescimento no número de matrículas em cursos de educação a distância para $82 \%$ no ano de 2015, contra apenas 5\% que acreditam na diminuição do número de alunos. Apesar disso, o censo aponta que a evasão continua sendo a grande vilã desta modalidade de ensino, com um percentual de $19,06 \%$ para os alunos de cursos regulamentados totalmente a distância, contra 10,49 \% para os alunos que cursam apenas disciplinas a distância.

Porque esta diferença estatística significativa entre a evasão que ocorre nos cursos online e àquelas dos cursos semipresenciais ou híbridos? Elisa Maria de Assis, diretora de EAD na Unopar², afirma que os pequenos índices de evasão em cursos a distância da instituição se devem a criação de um modelo de curso que cria laços sociais, fazendo com que o aluno não abandone o curso.

Muito se fala da necessidade de se humanizar a escola, o currículo e a educação (FREIRE, 2007; SANTOS NETO, 2004; SILVA, 1996; VASCONCELOS, 2003). No entanto, o que mais vemos são esforços visando à modernização das escolas, como a implantação dos programas "um computador por aluno" ou "tablets nas escolas" buscando criar um maior interesse nos alunos e diminuir a evasão. Segundo Marcelo Neri, ministro-chefe interino da Secretaria de Assuntos Estratégicos da Presidência da República, um dos grandes desafios hoje é criar condições para que a escola se modernize e volte a cativar os jovens ${ }^{3}$.

Contudo, conforme afirma Passarelli (2007), o fato das tecnologias estarem disponíveis não significa que elas serão utilizadas. É necessário saber usá-las de forma apropriada em termos de prática pedagógica para evitar que ocorra simplesmente a transferência do modelo pedagógico tradicional empirista ${ }^{4}$ para o ambiente virtual de aprendizagem sem uma mudança significativa na abordagem metodológica.

A realidade do uso inadequado ou da falta de ferramentas é a mesma na educação presencial ou na educação a distância. Analisando o resultado do censo EAD 2013/2014 podemos verificar que muitas das ferramentas que poderiam ser utilizadas para facilitar a interação e a participação dos

\footnotetext{
${ }^{1}$ Disponível em: http://www.abed.org.br/site/pt/midiateca/censo_ead/1272/2014/10/censoead.br_2013/2014. Acesso em abril de 2015.

${ }^{2}$ A Unopar (Universidade Norte do Paraná) foi a instituição com mais matrículas no ensino superior a distância segundo o Censo de Educação Superior 2010. Disponível em: https://www.listas.unicamp.br/pipermail/ead-l/2012-August/080478.html. Acesso em abril de 2015.

${ }^{3}$ Disponível em http://www.brasil.gov.br/educacao/2013/11/modernizar-a-escola-e-desafio-para-cativar-a-juventude. Acesso em abril de 2015.

${ }^{4} \mathrm{O}$ empirismo, no qual John Locke é considerado o principal representante, sustenta que o conhecimento está na realidade exterior e é absorvido por nossos sentidos. O professor é quem detém o saber. O aprendizado é obtido por meio da repetição, seguida da memorização.
} 
alunos ainda não são utilizadas. Um exemplo disso é a não adequação das instituições para disponibilizar o conteúdo do curso ou atividades para os dispositivos móveis. O assunto é tão pertinente que a UNESCO publicou um guia em 2013 com 10 dicas para usar celular na aula, mostrando os benefícios que esta prática pode trazer e buscando incentivar os governos a implantarem esses recursos nas salas de aula ${ }^{5}$. No entanto, das 309 instituições promotoras de ensino a distância, que responderam Censo EAD 2013/2014, 58,6\% ou seja, a maioria, não utiliza dispositivos móveis nos cursos oferecidos. Além disso, entre as instituições que utilizam os dispositivos móveis, somente $33,6 \%$ o fazem para disponibilizar conteúdos do curso; $15,7 \%$ só utiliza o serviço de SMS para enviar avisos aos alunos.

Também chamam a atenção, os números relacionados à utilização de ferramentas virtuais nos cursos oferecidos pelas instituições. Apesar de 80 \% das instituições afirmarem que conhecem ou utilizam as ferramentas virtuais, os números não revelam muita intimidade com o uso de ferramentas modernas na EAD. De acordo com o estudo, as ferramentas mais utilizadas foram: power point $(24,1 \%)$, youtube $(20,8 \%)$ e, google docs $(13,4 \%)$. Somente $5,1 \%$ citaram o uso de apps. (CENSO EAD 2013/2014).

Entre outras coisas, o censo detalha minuciosamente o uso e as expectativas da inserção das ferramentas da tecnologia da informação e da comunicação na EAD. Contudo, chama a atenção a mudança no foco entre o cenário dos investimentos já realizados e a previsão do que as instituições pretendem investir em 2015. O estudo aponta a diminuição no investimento na capacitação de tutores pelas instituições de ensino que responderam à pesquisa. O que podemos notar é um destaque para o aumento do uso das ferramentas tecnológicas, em detrimento do investimento no capital humano. A pesquisa aponta mais que o dobro de investimento em atividades como produção de jogos e produção em mobile learning e uma diminuição na produção de conteúdo e na capacitação de tutores.

Uma questão muito discutida no atual cenário é a figura do educador online ou tutor e a definição de quais competências e habilidades são necessárias para o desempenho desta função em cursos a distância. Jacquinot (2008), Mello(2010) e Passarelli (2007) ressaltam a importância da existência deste profissional que é responsável pelas interações, e mediações entre os alunos no ambiente virtual de aprendizagem para que ocorra um maior engajamento e um melhor desempenho dos alunos.

\footnotetext{
${ }^{5}$ Disponível em http://unesdoc.unesco.org/images/0021/002196/219641E.pdf. Acesso em abril de 2015. 
Igualmente, autores como Rovai e Barnum (2003), afirmam que a atuação do tutor e o desenvolvimento de atividades que permitam a participação e a interação entre os alunos, estão diretamente ligadas a uma maior satisfação com o curso e a uma aprendizagem mais profunda. No entanto, Mello (2010) aponta que apesar do MEC estabelecer desde 2007 a obrigatoriedade da presença do educador a distância nos cursos em EAD, não existe uma regulamentação sobre as atividades a ele designadas ou sobre a formação necessária para o desempenho desta atividade.

Além disso, pouco se fala sobre a implementação ou a necessidade de ferramentas que possibilitem um maior feedback dos alunos em relação à metodologia, ao conteúdo e à organização geral do curso em si. Conforme o censo 2013/2014 o motivo do alto índice de evasão (19,6\%) e principal obstáculo para a educação à distância é, segundo os alunos, a falta de adaptação à metodologia.

Mello (2010) defende que, para que ocorra a experiência educacional, há que se estabelecer a interface entre a presença cognitiva (pois um ambiente voltado às praticas educacionais deve apresentar eventos provocadores da cognição, exploração, integração e resolução), presença social (habilidade individual de interagir social e emocionalmente com os pares reduzindo a sensação emocional de distância física) e a presença educativa (construção do conhecimento, instruções sobre as atividades a serem desenvolvidas, gestão comunicacional e pedagógica do curso).

Segundo Palloff e Pratt (2007) para que os alunos tenham um maior engajamento nos cursos a distância, é necessária a criação de laços emocionais conseguidos através do sentimento de participação no grupo ou comunidade. Para que isso ocorra, o tutor online ou professor deverá estar em um relacionamento horizontal com os alunos, exercendo a função de facilitador das interações e incentivador das discussões. Os autores afirmam que a satisfação da necessidade de sentir-se parte de um grupo é o objetivo essencial, na educação à distância, superando inclusive o conteúdo do curso. Eles destacam a necessidade da formação de uma comunidade virtual, na qual os alunos possam se envolver emocionalmente com o grupo, agregando-se harmoniosamente. "A formação de uma comunidade de aprendizagem através da qual o conhecimento é partilhado e o significado é criado em conjunto, é o cenário para uma aprendizagem bem-sucedida." ${ }^{6}$ (PALLOFF; PRATT, 2007).

No entanto, faz-se necessário ressaltar que formar uma comunidade virtual não significa simplesmente participar de um grupo em uma rede social, postar e curtir fotos no facebook ou

\footnotetext{
${ }^{6}$ Tradução livre da autora para "the formation of a learning community through which knowledge is imparted and meaning is co-created set the stage for successful learning outcomes." 
comentários no twitter. A satisfação da necessidade de pertencer a um grupo social, de estar conectado com os outros, só acontece quando as pessoas compartilham práticas e ideais, quando tomam decisões em conjunto e quando elas se identificam como algo maior do que a soma dos relacionamentos individuais e estabelecem um elo duradouro consigo mesmos, com os outros e com o grupo (SHAFFER; ANUNDSEN, 1993).

Outros autores, como Picciano (2002), afirmam que é a implantação e utilização de ferramentas apropriadas, somadas ao auxílio do professor ou tutor que possibilitará para o aluno a satisfação da necessidade social de fazer parte de um grupo. Maslow (1943) já citava a importância da satisfação das necessidades sociais, do sentir-se participante de um grupo na sociedade como elemento fundamental na busca da autorrealização. A Hierarquia de Necessidade de Maslow é representada em cinco níveis dispostos em forma de pirâmide e, apresenta a ideia de que as ações humanas são direcionadas para o alcance de objetivos. A base da pirâmide compreende as necessidades fisiológicas e de segurança; o topo da pirâmide é constituído pelas necessidades da busca pela individualização do ser, como as necessidades sociais, de estima e por último, de autorrealização.

Freire (2002) destaca a importância de se implantar uma educação embasada nas interações dos alunos, para o estabelecimento de um diálogo entre eles e, o consequente desenvolvimento do pensamento crítico. Para ele, "O diálogo é a base de uma autêntica educação" (FREIRE,1983). O autor acrescenta que a educação problematizadora, a "educação libertadora" desperta no indivíduo a sua vocação em ser sujeito da sua própria realidade. Nesta perspectiva, contrária à educação bancária existe o diálogo e a troca de conhecimentos e experiências:

“o educador já não é o que apenas educa, mas o que, enquanto educa é educado, em diálogo com o educando que, ao ser educado, também educa. Ambos, assim, se tornam sujeitos do processo em que crescem juntos e em que os argumentos de autoridade já não valem" (FREIRE, 2002, p.68).

Quando tratamos sobre a valorização do conhecimento prévio do aluno, muito se fala sobre metodologias ativas na educação presencial, como a aprendizagem baseada em problemas, a problematização (AGUILAR; TSUJI, 2010) e; a aprendizagem significativa (SCHLÜNZEN,2000), na qual o ensino/aprendizagem é contextualizado e construcionista levando em consideração valores, conhecimentos, estilos de aprendizagem e interesses individuais. Apesar de serem abordagens metodológicas diferentes, nestes processos o aluno é responsável e protagonista no de 
ensino/aprendizagem e as interações dialógicas e compartilhamento de informações são fundamentais.

Apesar da predominância do uso destes métodos no ensino presencial ou híbrido, existem autores como Moran (2013) que pregam à utilização de metodologias ativas no ensino a distância, em cursos mais personalizados nos quais a abordagem de ensino seja contextualizada, com ênfase na colaboração e na pesquisa e que contemple os estilos de aprendizagem dos alunos.

"caminhamos de uma EAD mais industrial, massiva, de produto pronto, igual para todos, para modelos bem mais flexíveis, que combinam o melhor dos percursos individuais com momentos de aprendizagem em grupo, de colaboração intensa. As tecnologias WEB 2.0, gratuitas e colaborativas, facilitam a aprendizagem entre colegas, próximos e distantes. Tudo caminha para ser mais aberto, ágil, intuitivo." (MORAN, 2013)

Nesta mesma linha de pensamento na busca pela formação do pensamento crítico e de sujeitos conscientes, encontram-se os autores que falam sobre a inter-relação entre educação e comunicação ou a educomunicação. Segundo Soares (2000), firma-se um referencial teórico que sustenta a inter-relação comunicação/educação como campo de diálogo, espaço para o conhecimento crítico e criativo, para a cidadania e a solidariedade.

Partindo dos pressupostos das práticas educomunicativas, de valorização do diálogo colaborativo e reflexivo, "na transformação dos espaços comunicativos em ecossistemas comunicacionais expressivos" (SOARES, 2000),

\section{METODOLOGIA}

Para as reflexões acerca do tema proposto, adotou-se como procedimento metodológico a pesquisa de cunho bibliográfica, através da leitura crítica-reflexiva dos conteúdos propostos dentro desta temática. O foco da busca e análise do conteúdo foi o de apresentar uma visão abrangente sobre a situação atual da EAD no Brasil, apresentando as lacunas existentes, mas também, alternativas e possibilidades que podem trazer benefícios e a superação de barreiras.

\section{CONSIDERAÇÕES FINAIS}

Após leitura, analise e reflexões sobre o atual cenário da EAD identificado através dos estudos realizados pela ABED e as publicações de pesquisadores, pudemos notar que são escassas as 
pesquisas referentes ao estudo das práticas educomunicativas em EAD, constando apenas dois trabalhos nesta temática no Banco de Teses e Dissertações da Capes e, o enfoque dos autores é nas mediações realizadas pelo tutor. Além disso, também são poucos os estudos, no Brasil, sobre o uso de metodologias ativas em ambientes virtuais de aprendizagem. No entanto, vale a pena ressaltar que a variedade de alternativas e trabalhos disponíveis demonstra um amadurecimento dos estudos nesta temática com a apresentação de boas práticas e modelos a serem seguidos pelas IES que tiverem interesse em uma abordagem metodológica que leve em consideração os diferentes estilos de aprendizagem dos alunos, oferecendo atividades e ferramentas que promovam a autonomia do aluno, a capacidade de pesquisar com qualidade e criticidade, e a interação entre pares para a produção colaborativa do conhecimento.

\section{REFERÊNCIAS}

AGUILAR, Rinaldo; TSUJ, Hissachi. A Gestão do Conhecimento em Metodologias Ativas de Ensino Aprendizagem: uma reflexão do trabalho desenvolvido na Faculdade de Medicina de Marília. Revista Gestão \& Tecnologia, [S.I.], v. 6, n. 2, set. 2010. ISSN 2177-6652. Disponível em: <http://revistagt.fpl.edu.br/get/article/view/179/174>. Acesso em: 14 ago. 2015.

FREIRE, Paulo. Extensão ou comunicação? Rio de Janeiro: Paz e Terra, 1983.

. Educação e mudança. 26. ed. Rio de Janeiro: Paz e Terra, 2002.

Paz e Terra, 2007.

Pedagogia da Autonomia: saberes necessários à prática educativa. 35 ed. São Paulo: . Pedagogia do oprimido. 29 ed. Rio de Janeiro:Editora Paz e Terra. 1987.

JACQUINOT, Geneviéve. Acompagner lês apprentissages: le tutorat pièce maitresse et parent pauvre des dispositifs de formation médiatisés, in L'Université Et lês TIC, Chronique dune innovation annoncée. Paris: Groupe de Boeck, 2008.

LAVILLE, Christian. A construção do saber. Porto Alegre: Artes Médicas Sul, 1999.

MASLOW, Abraham H. A preface to motivation theory. Psychosomatic Med., 1943, 5, 85-92. http://dx.doi.org/10.1097/00006842-194301000-00012

MELLO, Luci Ferraz de. Educomunicação na Educação à Distância: o Diálogo a partir das Mediações do Tutor. Dissertação de Pós-Graduação em Ciência da Comunicação da USP. São Paulo, 2010. Disponível em: www.teses.usp.br/teses/disponiveis/27/27154/tde.../LuciFerrazMello.pdf. Acesso em março de 2015. 
MORAN, José. A educação a distância, mais focada em pesquisa e colaboração. In: FIDALGO, Fernando (Org.). Educação a Distância: Meios, Atores e Processos. Belo Horizonte: CAED-UFMG, 2013, p. 39-51.

PALLOFF, Rena; PRATT, Keith. Building online learning communities: Effective strategies for the virtual classroom. San Francisco: Jossey-Bass, 2007.

PASSARELLI, Brasilina. (Org.) Cibercultur@, comunidades e relações de poder: uma produção coletiva. São Paulo: Escola de Comunicações e Artes da Universidade de São Paulo - ECA/USP, 2007. $165 p$.

PICCIANO, Anthony G. Beyond student perceptions: Issues of interaction, presence, and performance in an online course. Journal of Asynchronous Learning Networks, 6(1), 21-38, 2002.

ROVAI, Alfred; BARNUM, K. On-line course effectiveness: An analysis of student interaction and perception of learning. Journal of Distance Education, 18(1), 57-73,2003.

SANTOS NETO, Elydio dos. Esperança, utopia e resistência na formação e prática de educadores no contexto neoliberal. In: Revista de Educação do COGEIME, ano 13, no. 24, Piracicaba: COGEIME, p. 5362, junho de 2004.

SHAFFER, Carolyn; ANUNDSEN, Kristin. Creating community anywhere. New York: Jeremy P. Tarcher/ Perigee Books, 1993.

SILVA, Jair Militão da. A autonomia da escola pública: a re-humanização da escola. Campinas:Papirus, 1996.

SOARES, Ismar de Oliveira. Educomunicação: um campo de mediações. Comunicação \& Educação. São Paulo: ECA/USP-Editora Segmento, Ano VII, set/dez. 2000, № 19.

Mas, afinal, o que é educomunicação?[S.I.]: Núcleo de Comunicação e Educação da

Universidade de São Paulo, [S.D.]. Disponível em: http://www.usp.br/nce/aeducomunicacao/saibamais/textos. Acesso em abril de 2015.

. Educomunicação: Um campo de mediações. In: CITELLI, A. O.; COSTA, M. C. C. (Org.). Educomunicação: construindo uma nova área de conhecimento. São Paulo: Paulinas, 2011.

SCHLÜNZEN, Elisa. Mudanças nas Práticas Pedagógicas do Professor: Criando um Ambiente Construcionista, Contextualizado e Significativo para Crianças com Necessidades Especiais Físicas. Dissertação de Doutorado na PUC, 2000.

VASCONCELOS, Celso dos Santos. Para onde vai o Professor? Resgate do Professor como sujeito de transformação. 10a Ed. São Paulo: Libertad, 2003. 